\title{
VISIBLE LIGHT PHOTOINITIATION OF MESENCHYMAL STEM CELL-LADEN BIORESPONSIVE HYDROGELS
}

\author{
C.S. Bahney ${ }^{1,2}$, T.J. Lujan ${ }^{3}$, C.W. Hsu ${ }^{4}$, M. Bottlang ${ }^{3}$, J.L. West ${ }^{4}$ and B. Johnstone ${ }^{1,2 *}$ \\ ${ }^{1}$ Department of Orthopaedics and Rehabilitation, and ${ }^{2}$ Department of Cell and Developmental Biology, Oregon \\ Health \& Science University (OHSU), Portland, OR, USA \\ ${ }^{3}$ Biomechanics Laboratory, Legacy Research \& Technology Center, Portland, OR, USA \\ ${ }^{4}$ Department of Bioengineering, Rice University, Houson, TX, USA
}

\begin{abstract}
Biological activity can be added to synthetic scaffolds by incorporating functional peptide sequences that provide enzyme-mediated degradation sites, facilitate cellular adhesion or stimulate signaling pathways. Poly(ethylene glycol) diacrylate is a popular synthetic base for tissue engineering scaffolds because it creates a hydrophilic environment that can be chemically manipulated to add this biological functionality. Furthermore, the acrylate groups allow for encapsulation of cells using photopolymerization under physiological conditions. One complication with the addition of these peptides is that aromatic amino acids absorb light at $285 \mathrm{~nm}$ and compete with the ultraviolet (UV)-sensitive photoinitiators such as Irgacure ${ }^{\mathrm{TM}} 2959$ (I2959), the most commonly used initiator for cytocompatible photoencapsulation of cells into synthetic scaffolds. In this study we define non-toxic conditions for photoencapsulation of human mesenchymal stem cells (hMSC) in PEGDA scaffolds using a visible light photoinitiator system composed of eosin $\mathrm{Y}$, triethanolamine and 1-vinyl-2-pyrrolidinone. This visible light photoinitiator produced hydrogel scaffolds with an increased viability of encapsulated hMSCs and a more tightly crosslinked network in one-third the time of UV polymerization with I2959.
\end{abstract}

Keywords: Eosin Y, visible light photoinitiator, bioresponsive hydrogels, photoencapsulation, photopolymerization, dynamic modulus, tissue engineering, mesenchymal stem cells.
* Address for correspondence:

Brian Johnstone

Oregon Health \& Science University

Department of Orthopaedics \& Rehabilitation, OP31

3181 Sam Jackson Park Road

Portland OR 97239, USA

E-mail: johnstob@ohsu.edu

\section{Introduction}

Tissue engineering is an experimental concept that has been in the literature for approximately 25 years, with an application to cartilage first introduced in the early 1990s (Ringe and Sittinger, 2009). A principle of cartilage engineering is to utilize three-dimensional scaffolds to support chondrogenic cells and facilitate the development of a neocartilaginous construct that can functionally replace damaged or diseased tissue in vivo. The role of the scaffold has evolved towards an instructive microenvironment that can facilitate cell migration, differentiation, adhesion, and cell-mediated degradation (Lutolf and Hubbell, 2005; Hwang et al., 2008; Lutolf, 2009). In many cases adding these biological activities to the scaffold requires the spatiotemporal incorporation of peptides. As we advance our understanding of what biological functionality needs to be added to scaffolds for improved neotissue formation, it becomes essential to expand our range of techniques for scaffold development, specifically with respect to the impact of scaffold formation on the cells.

Synthetic scaffolds such as poly(ethylene glycol) diacrylate (PEGDA) are popular biomaterials for tissue engineering because their physical and chemical properties can be easily tailored to suit the individual needs of developing tissue. For example, we, and others, have previously demonstrated that physical modifications to the scaffold can result in significant changes to matrix production and distribution in cartilage engineering applications (Bryant et al., 1999b; Bryant et al., 2004; Buxton et al., 2007; Erickson et al., 2009). Furthermore, the inclusion of cell adhesion ligands (Mann et al., 2001a; Harbers and Healy, 2005; Hwang et al., 2006; Salinas and Anseth, 2008), growth factors (Suzuki et al., 2000; Mann et al., 2001b; Fan et al., 2007; Wall et al., 2008), and enzymatic cleavage sites (West and Hubbell, 1999; Kim et al., 2005; Rice et al., 2006) can chemically modify scaffolds to make them bioactive and bioresponsive [see recent reviews: (Kohane and Langer, 2008; Lutolf et al., 2009; Place et al., 2009)].

Another specific advantage of PEGDA scaffolds is that they can be formed under physiological conditions through the process of photopolymerization, which allows for the uniform encapsulation of cells (Graham, 1998a,b; Nguyen and West, 2002). Photopolymerization uses light to dissociate initiator molecules into free radicals that can react with macromers functionalized with double or triple chemical bonds (i.e. the acrylate groups in PEGDA) to propagate radical chain polymerization. One problem with this system is that free radicals created during this process can have the unintended 

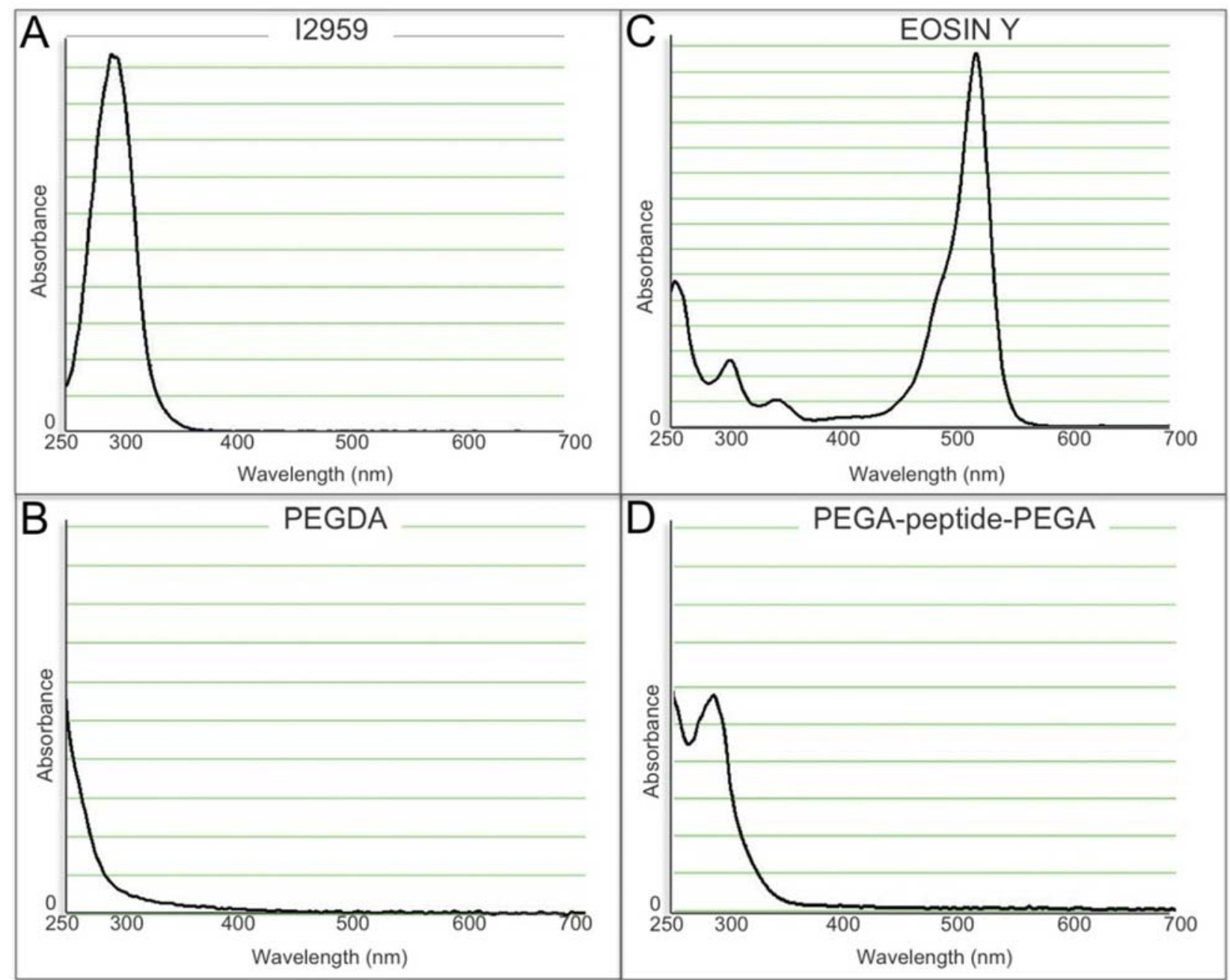

Fig. 1. Spectrophotometric absorbance of (A) Irgacure ${ }^{\mathrm{TM}} 2959$ UV sensitive photoinitiator, (B) $10 \%$ (w/v) PEGDA macromer, (C) Eosin Y photosensitizer, (D) $10 \%$ (w/v) peptide containing PEGDA macromer.

side effect of damaging cell membranes, proteins and DNA. Consequently, considerable effort has been made into finding cytocompatible photoinitiators. The most well established initiator system for photoencapsulation is Irgacure ${ }^{\mathrm{TM}} 2959$ (1-[4-(2-Hydroxyethoxy)-phenyl]-2hydroxy-2-methyl-1-propane-1-one, "I2959") used in combination with ultra violet (UV) light. Although I2959 is tolerated by many cell types at a concentration of 0.03-0.1 \% (Bryant et al., 2000; Williams et al., 2005; Fedorovich et al., 2009), it has been shown that different cell types will display differential toxicity to both the I2959 and UV light (Williams et al., 2005). I2959 has peak absorbance of $\sim 280 \mathrm{~nm}$ (Fig. 1A), but is often used with light filtered to $365 \mathrm{~nm}$ to mitigate some of the mutagenic effects of the lower wavelength UV light despite a significantly reduced molar extinction (4 M-1 $\left.\mathrm{cm}^{-1}\right)$ (Bryant et al., 1999b).

Both the direct incorporation of peptide sequences into the monomer backbone and tethering of peptides is central to the design of the bioactive, biomimetic, and bioresponsive scaffolds discussed above. However, aromatic amino acids absorb at $285 \mathrm{~nm}$, thus competing with I2959 during photoinitiaton (Fig. 1D). High concentrations of I2959 can outcompete the effect of the peptide. However, cellular toxicity is clearly documented at concentrations above 0.1 \% (Bryant et al., 2000; Williams et al., 2005; Fedorovich et al., 2009). One potential solution is to use a photoinitiator active outside of the UV range. In this study, we validated a visible light initiator system composed of eosin $\mathrm{Y}$, which has peak absorbance at $\sim 510 \mathrm{~nm}$ (Fig. 1C), triethanolamine (TEA), and 1-vinyl-2 pyrrolidinone (NVP) for the photoencapsulation of human mesenchymal stem cells (hMSCs). This photoinitiator system has previously been studied in regards to islet cell viability and encapsulation efficiencies using an argon ion laser (Cruise et al., 1998) and visible light photoencapsulation of a fibroblast cell line MRC-5 (Bikram et al., 2007). However, we found the photoinitiator concentrations used in those studies to be toxic for the photoencapsulation of hMSCs. Here we define significantly lower concentration of both eosin Y and TEA that can be used to effectively facilitate polymerization while avoiding the cytotoxicity of these reagents.

\section{Materials and Methods}

\section{Preparation of PEGDA}

Poly(ethylene glycol) diacrylate (PEGDA, $6 \mathrm{kDa}$ ) was synthesized as previously described (Mann et al., 2001b). PEGDA was prepared by combining $0.1 \mathrm{mM}$ dry PEG with $0.4 \mathrm{mM}$ acryloyl chloride and $0.2 \mathrm{mM}$ triethylamine 
A

\begin{tabular}{|c|c|c|c|}
\hline Category & $\begin{array}{c}\text { TEA } \\
(\%)\end{array}$ & $\begin{array}{c}\text { Eosin } \mathbf{Y} \\
(\mathbf{m M})\end{array}$ & $\begin{array}{c}\text { Complete } \\
\text { Polymerization? }\end{array}$ \\
\hline A & 1.500 & 0.100 & yes \\
\hline B & 0.750 & 0.100 & yes \\
\hline C & 0.100 & 0.010 & yes \\
\hline D & 0.100 & 0.005 & yes \\
\hline E & 0.050 & 0.010 & yes \\
\hline F & 0.050 & 0.005 & yes \\
\hline G & 0.010 & 0.010 & no \\
\hline H & 0.010 & 0.100 & no \\
\hline I & 0.050 & 0.001 & no \\
\hline
\end{tabular}

Fig. 2. Screening design for lower visible light initiator conditions. (A) Table of input parameters, (B) Dynamic modulus response model, (C) Dynamic compressive modulus (** groups were significantly different than the other groups and each other by Tukey's HSD multiple comparison test, $p<0.05$ ), (D) Swelling ratio (* groups were significantly different than the other groups, but not than each other by Tukey's HSD multiple comparison test, $p<0.05$ ).

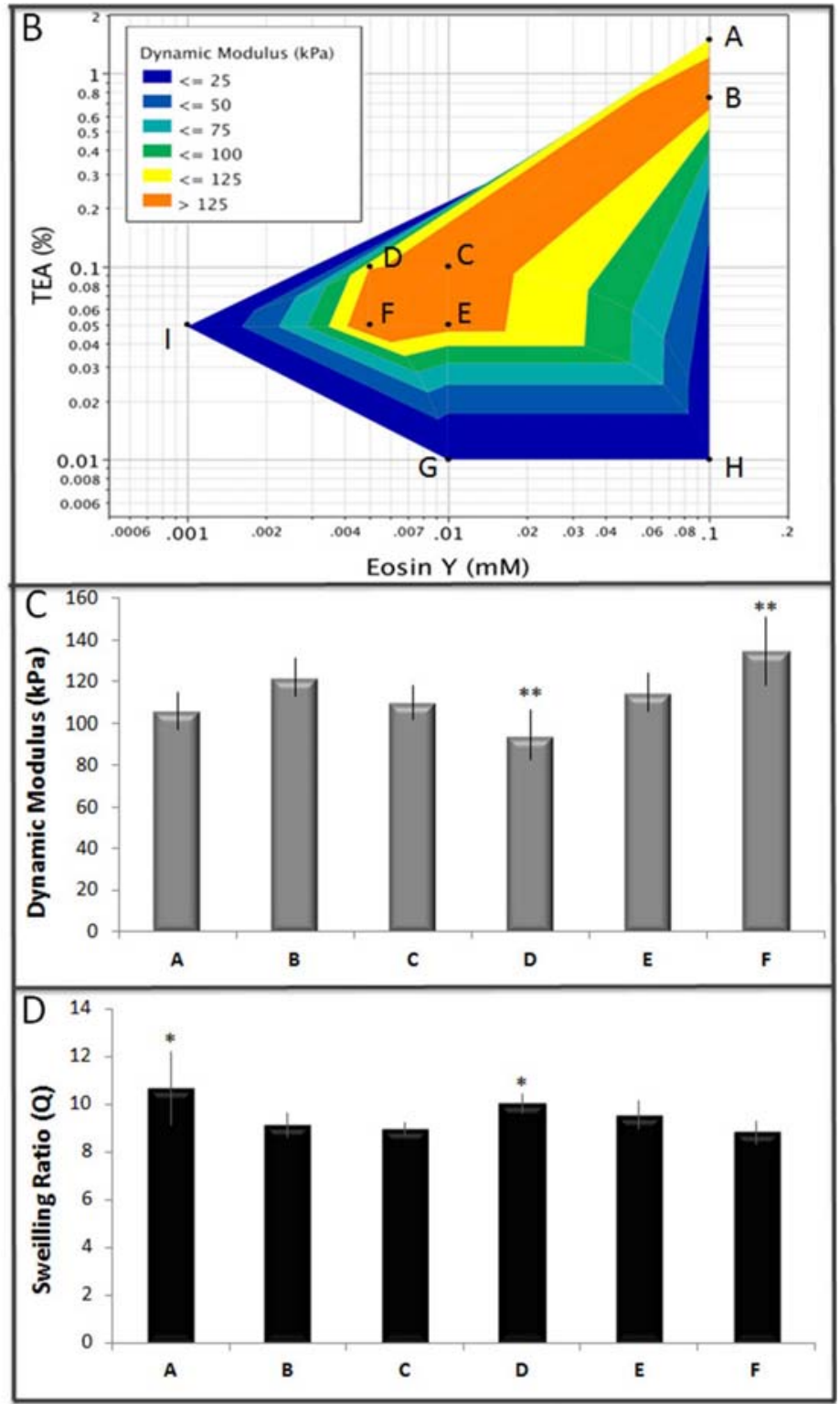

Table 1. Macromer chemistry for hydrogels.

\begin{tabular}{lc}
\hline Acronym & Macromer Chemistry \\
\hline PEGDA & $10 \%(\mathrm{w} / \mathrm{v}), 6 \mathrm{kDa}$ \\
sIPN & poly(ethylene glycol) diacrylate \\
\hline \multirow{2}{*}{ PEGA-peptide-PEGA } & $16 \%$ PEGDA $+32 \%$ PEG \\
& semi-interpenetrating network \\
\hline
\end{tabular}

in anhydrous dichloromethane and stirred under argon overnight. The mixture was then precipitated in cold ethyl ether, vacuum dried overnight, lyophilized, and stored at $4{ }^{\circ} \mathrm{C}$. The concept of a bioresponsive hydrogel was modeled by embedding a commercially fabricated peptide into the PEGDA backbone; any peptide sequence of interest could be used in this application, we chose to use GGWGGMLLVTPSGGGK, which is not known to have any biological activity (Rawlings et al., 2008). This peptide was covalently conjugated to acrylate-PEG-succinimidyl carboxymethyl (a-PEG-SCM, 3,400 Da; Laysan Bio Inc,
Arab, AL, USA) through the reactive lysines at both the $\mathrm{N}$ - and $\mathrm{C}$ - termini using a 1:2.1 (peptide/PEG) molar ratio in DMSO (Sigma-Aldrich, Milwaukee, WI, USA) for $24 \mathrm{~h}$ at room temperature. Diisopropylamine (DIPEA, SigmaAldrich) was added as a base catalyst at a 2:1 (DIPEA/ PEG) molar ratio into the reaction. The resulting solution was then diluted in $10 \mathrm{~mL}$ of ultrapure water and purified by dialysis (MWCO 3500 Da; Fisher Scientific, Pittsburg, PA, USA) against deionized water for $24 \mathrm{~h}$. The purified monomer was lyophilized and stored under argon at $-20^{\circ} \mathrm{C}$. The conjugation products were analyzed by gel permeation 


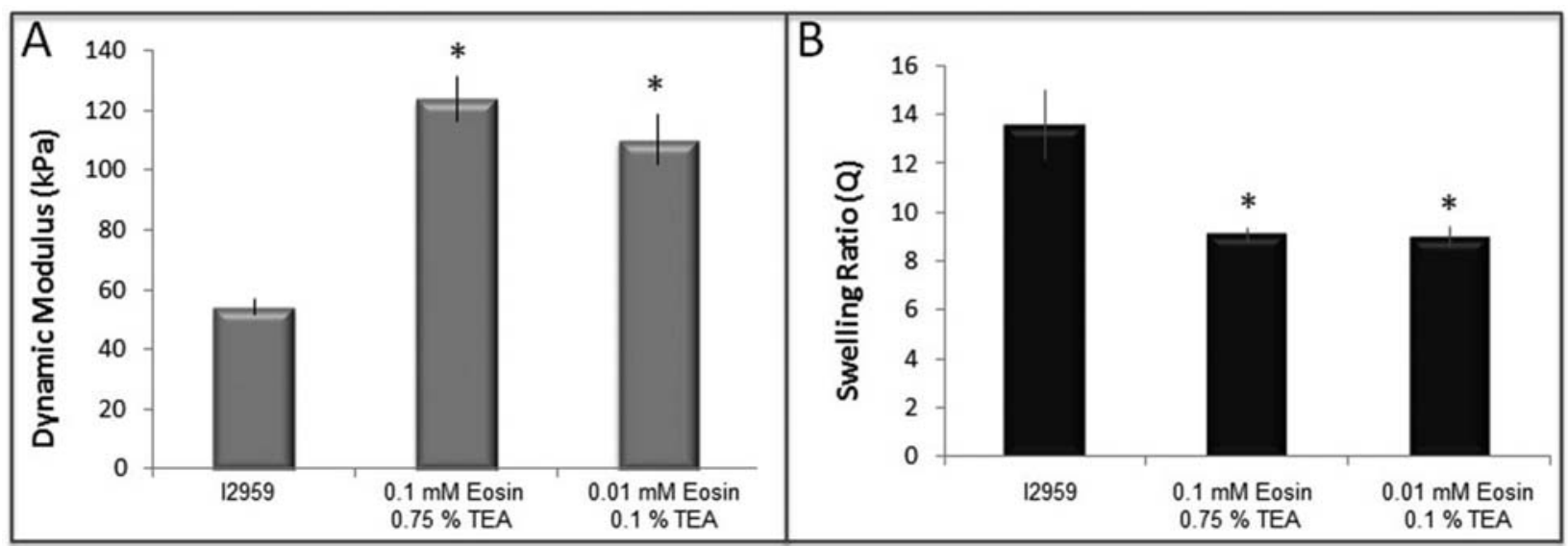

Fig. 3. Scaffold parameters of visible light initiation compared to UV light initiation. (A) Dynamic compressive modulus $(p<0.0001)$, (B) Swelling ratio $(p<0.005)$.

chromatography (GPC, Polymer Laboratories, Amherst, MA, USA) with UV-vis and evaporative light scattering detectors and the presence of the acrylate groups was verified using nuclear magnetic resonance (NMR). The absorbance spectra for PEGDA and PEGA-peptide-PEGA are shown in Figs. 1B, D respectively. Absorbance was read from 220 to $700 \mathrm{~nm}$ using a Nanodrop Spectrophotometer according to manufacturer's protocol.

\section{Hydrogel synthesis}

Cell-free hydrogels were prepared from a $10 \%(\mathrm{w} / \mathrm{v})$ PEGDA solution and photopolymerized using either ultra violet (UV, Spectroline ENF-260C) or visible light (Bartels \& Stout V-LUX 1000). The water-soluble UV light photoinitiator Irgacure ${ }^{\circledR} 2959$ (1-[4-(2-Hydroxyethoxy)phenyl]-2-hydroxy-2-methyl-1-propane-1-one, "I2959”, $\mathrm{Ciba}^{\circledR}$, Tarrytown NY, USA) was used to define the control conditions. Disk-shaped hydrogels ( $8 \mathrm{~mm}$ diameter x $2 \mathrm{~mm}$ height) were formed by mixing $10 \%$ PEGDA macromer with 0.06 \% I2959 dissolved in PBS; macromer was placed into a custom-built stainless steel mold and exposed to 6 min UV light (365 nm, $\left.\sim 6 \mathrm{~mW} / \mathrm{cm}^{2}\right)$. I2959's peak absorbance is $280 \mathrm{~nm}$ (Fig. 1A) but remains an effective photoinitiator for PEGDA at $365 \mathrm{~nm}$ (Bryant et al., 1999a; Bryant et al., 2000).

The visible light initiating system included the photosensitizer eosin Y, initiator triethanolamine (TEA), and catalyst 1-vinyl-2 pyrrolidinone (NVP). Eosin Y has a peak absorbance at $510 \mathrm{~nm}$ (Fig. 1C). To establish the effective limits of the visible light initiator system the concentrations of both eosin Y and TEA were systematically adjusted and polymerization characterized (Fig. 2 and Table 1). Hydrogels were synthesized in a similar fashion to that described for UV light fabrication. Briefly, $10 \%(\mathrm{w} / \mathrm{v})$ PEGDA macromer solution was prepared with 0.001-0.1 mM eosin Y, 0.05-0.75\% TEA, and $37 \mathrm{nM}$ NVP. Macromer was photopolymerized under visible light in the mold for $2 \mathrm{~min}$.

\section{Mechanical testing}

Material properties of the hydrogels were measured with a custom apparatus that imposed unconfined compression to cell free scaffolds (Lujan et al., 2011). Specimens were compressed by a voice-coil force actuator that was controlled using data acquisition software and hardware (National Instruments, LabView 8.0, PCI 6221, Austin TX, USA). The actuator applied an upward force to a rigidly connected plunger to compress specimens into an impermeable aluminum platen (15 $\mathrm{mm}$ diameter). Compressive forces were measured by connecting the platen to a rigidly fixed load cell (Sensotec, Morristown, NJ, USA; resolution $0.005 \mathrm{~N}$ ). Specimen displacement was measured with a glass-scale encoder integrated into the voice-coil actuator (resolution $=1 \mu \mathrm{m}$ ). The actuator was powered with a linear current amplifier and the load cell was powered by a signal conditioner with a low-pass filter (Omega, Standord, CT, USA). In the absence of a testing specimen, the test system yielded a dynamic stiffness of 1 $\mathrm{N} / \mu \mathrm{m}$, which is over two orders of magnitude greater than the dynamic stiffness of standard hydrogels (Kisiday et al., 2004). This force-controlled testing system was selected to ensure that the platen would not lift-off the specimen during testing (Park et al., 2004a).

For each material test, specimens were centered in a culture dish filled with $1 \mathrm{~mL}$ phosphate buffered saline (PBS), and loaded into the testing apparatus. To establish a consistent reference position for all samples, a $0.1 \mathrm{~N}$ preload was applied and specimen thickness was recorded $\left(l_{o}\right)$. The samples were then loaded to $0.4 \mathrm{~N}$ and allowed 90 $\mathrm{s}$ to creep. Sinusoidal force waves were then applied for 30 cycles at $1 \mathrm{~Hz}$ to an amplitude of $0.5 \mathrm{~N}$ (peak-to-peak). These forces resulted in an average dynamic compression between $5 \%$ and $20 \%$ strain (Woodfield et al., 2004).

Dynamic compressive modulus was calculated as the ratio of the first Piola-Kirchhoff stress (force in the present configuration divided by area in the reference configuration) and engineering strain $\left(\left(l-l_{o}\right) / l_{o}\right.$, where $l$ is the current thickness and $l_{o}$ is the reference thickness). These values were extracted by fitting the final three cycles of stress and strain data to a four-parameter sine function in LabView (Lujan et al., 2009). Data measurements represent means \pm standard deviation; between 4 and 12 replicate constructs were measured for each condition. Data was analyzed using an ANOVA with significance set at 0.05, followed by Tukey's HSD (Fig. 2) or a pairwise comparison to the control using Dunnett's test (Fig. 3). 


\section{Swelling ratio and mesh size calculations}

Cell-free scaffolds were fabricated as described above and swollen to equilibrium in PBS (minimum of $60 \mathrm{~h}$ ) at $37{ }^{\circ} \mathrm{C}$ and $5 \% \mathrm{CO}_{2}$. After reaching equilibrium scaffolds were weighed $\left(\mathrm{W}_{\mathrm{eq}}\right)$ and then dried in a vacuum chamber (Thermo Vacuum Oven Model \#19: minimum of $48 \mathrm{~h}$ at $37{ }^{\circ} \mathrm{C}, 25 \mathrm{mmHg}$ ) to determine dry weight $\left(\mathrm{W}_{\text {dry }}\right)$. The volumetric swelling ratio $(\mathrm{Q})$ was determined using the following equation:

$$
Q=\left(\frac{W_{e q}-W_{d r y}}{W_{d r y}}\right)
$$

Data measurements represent means \pm standard deviation; between 4 and 12 replicate constructs were measured for each condition. Data was analyzed using an ANOVA with significance set at 0.05 , followed by Tukey's HSD (Fig. 2) or a pairwise comparison to the control using Dunnett's test (Fig. 3).

The molecular weight between crosslinks $\left(\mathrm{M}_{\mathrm{C}}\right)$ can be approximated using the Peppas-Merrill model (Peppas and Merrill, 1976), which was modified from the Flory-Rehner model (Flory and Rehner, 1943):

$$
\frac{1}{M_{C}}=\frac{2}{M_{n}}-\frac{\frac{v}{V_{1}}\left[\ln \left(1-V_{2, s}\right)+V_{2, s}+\mu V_{2, s}^{2}\right]}{V_{2, r}\left[\left(\frac{V_{2, s}}{V_{2, r}}\right)^{\frac{1}{3}}-\frac{1}{2}\left(\frac{V_{2, s}}{V_{2, r}}\right)\right]}
$$

Here $M_{n}$ is the number average molecular weight of the polymer, $\mathrm{n}$ is the specific volume of bulk PEG in the amorphous state $\left(0.893 \mathrm{~cm}^{3} / \mathrm{g}\right), \mathrm{V}_{1}$ is the molar volume of the solvent $\left(18 \mathrm{~cm}^{3} / \mathrm{mol}\right), \mathrm{m}$ is the Flory-Huggins polymersolvent interaction parameter ( 0.426 for PEG-water as determined by Merrill et al. (Merrill et al., 1993)), and $\mathrm{V}_{2, \mathrm{r}}$ and $\mathrm{V}_{2, \mathrm{~s}}$ are the volume fraction of the polymer at the relaxed state and swelling equilibrium, respectively. $\mathrm{V}_{2, \mathrm{r}}$ is equivalent to the volume concentration of the solution where crosslinking occurs $(14.3 \%) . \mathrm{V}_{2, \mathrm{~s}}$ is equal to the reciprocal of the volumetric swelling ratio $\left(\mathrm{v}_{2, \mathrm{~s}}=\mathrm{V}_{\mathrm{p}} / \mathrm{V}_{\mathrm{eq}}\right.$ $=1 / \mathrm{Q} ; \mathrm{V}_{\mathrm{p}}=$ dry volume, $\mathrm{V}_{\mathrm{eq}}=$ volume in the equilibrium swollen state of the gel).

The mesh size $\xi$ can be calculated on the basis of (Canal and Peppas, 1989):

$$
\xi=v_{2, s}{ }^{-\frac{1}{3}}\left(r_{0}^{2}\right)^{\frac{1}{2}}
$$

where $\left(r_{0}^{2}\right)^{\frac{1}{2}}$ is the unperturbed mean-square end-to-end distance of the PEG:

$$
\left(r_{0}^{2}\right)^{\frac{1}{2}}=l\left(\frac{2 M_{C}}{M_{r}}\right)^{\frac{1}{2}} C_{n}^{\frac{1}{2}}
$$

and $l$ is the average value of the bond length between $\mathrm{C}-\mathrm{C}$ and $\mathrm{C}-\mathrm{O}$ bonds in the $\mathrm{PEG}$ repeat unit $\left[-\mathrm{O}-\mathrm{CH}_{2}-\mathrm{CH}_{2}-\right]$ (1.46 $\mathrm{A}), \mathrm{M}_{\mathrm{r}}$ is the molecular mass of the PEG repeat unit (44 $\mathrm{g} / \mathrm{mol}$ ), and $\mathrm{C}_{\mathrm{n}}$ is the characteristic ratio for PEG (Bryant and Anseth, 2003).

\section{Mesenchymal stem cell isolation and culture}

Mesenchymal stem cells (MSCs) were isolated and expanded from human iliac crest bone marrow aspirates as previously described (Buxton et al., 2007; Johnstone et al., 1998; Yoo et al., 1998). Briefly, human bone marrow was obtained from the iliac crests of consenting donors. Marrow aspirates were fractionated on a Percoll density gradient and plated in Dulbecco's modified Eagle's medium (DMEM) with $10 \%$ fetal bovine serum (FBS). Adherent cells were cultured at $37^{\circ} \mathrm{C}, 5 \% \mathrm{CO}_{2}$ with medium changes every four days. Once primary cells were confluent, cells were passaged for expansion and the serum-containing DMEM was supplemented with fibroblast growth factor (FGF-2, $10 \mathrm{ng} / \mathrm{mL}$ ) for retention of chondrogenic potential. Expanded human MSCs (hMSCs) were used following 3 to 12 population doublings (passages 1 to 3 ).

\section{Cellular encapsulation and culture}

Expanded hMSCs were photoencapsulated in a variety of PEGDA-based hydrogels using either the UV or visible light systems described above: macromer chemistries used for this study are detailed below in Table 1. For photoencapsulation of hMSCs with UV-light, macromer was swollen in PBS to twice the final concentration (w/v), filter sterilized using a $0.2 \mu \mathrm{m}$ syringe, and then combined with $0.06 \%(w / v)$ I 2959 and the balance volume of a cell-solution containing $25 \times 10^{6} \mathrm{hMSCs} / \mathrm{mL}$ (Buxton et al., 2011). This mixture was then photopolymerized into disk-shaped hydrogels ( $8 \mathrm{~mm}$ in diameter $\mathrm{x} 2 \mathrm{~mm}$ thick) by adding the monomer into a custom-built stainless steel mold and exposing the mixture to $6 \mathrm{~min}$ of long-wave UV light $\left(365 \mathrm{~nm}, 6 \mathrm{~mW} / \mathrm{cm}^{2}\right)$ from the top. Hydrogels polymerized under visible light were made to test two concentrations of photoinitiator validated by the mechanical testing described above: $0.75 \%$ TEA with $0.1 \mathrm{mM}$ eosin Y, or $0.1 \%$ TEA with $0.01 \mathrm{mM}$ esoin Y. Macromer was dissolved in TEA to twice the final concentration and filter sterilized before being diluted with an equal volume solution containing 25 x $10^{6} \mathrm{hMSCs} / \mathrm{ml}$, eosin Y, and NVP. Disk-shaped hydrogels were fabricated following a 2 min exposure to visible light from a microscope light (Bartels \& Stout V-LUX 1000). Hydrogels were cultured at $37^{\circ} \mathrm{C}, 5 \% \mathrm{CO}_{2}$ for six weeks in a defined chondrogenic medium (Johnstone et al., 1998; Yoo et al., 1998). The defined medium consisted of high-glucose DMEM with $\mathrm{ITS}^{+}$Premix (Collaborative Biomedical Products, Bedford, MA, USA), sodium pyruvate $(1 \mathrm{mM})$, ascorbate-2-phosphate $(37.5 \mu \mathrm{g} / \mathrm{mL})$, dexamethasone $\left(10^{-7} \mathrm{M}\right)$, TGF- $\beta 1(10 \mathrm{ng} / \mathrm{mL}$, recombinant human, Peprotech, Rocky Hill, NJ, USA) and l-glutamine (4 mM).

\section{Live-dead staining}

Cellular toxicity for the photoinitiator system for hMSCs photoencapsulation was visualized following $48 \mathrm{~h}$ of in vitro culture in defined chondrogenic medium using a Live-Dead Viability/Cytotoxicity Kit (Invitrogen/Life Technologies, Carlsbad, CA, USA; L-3224). This kit distinguishes live cells by the conversion of the nonfluorescent calcein AM to the green fluorescent calcein through intercellular esterase activity. Dead cells are stained with ethidium homodimer-1 (EthD-1), which is excluded by live cells, but fluoresces red upon uptake and binding to the intercellular nucleic acids in dead cells. Hydrogels were rinsed twice with PBS and then 

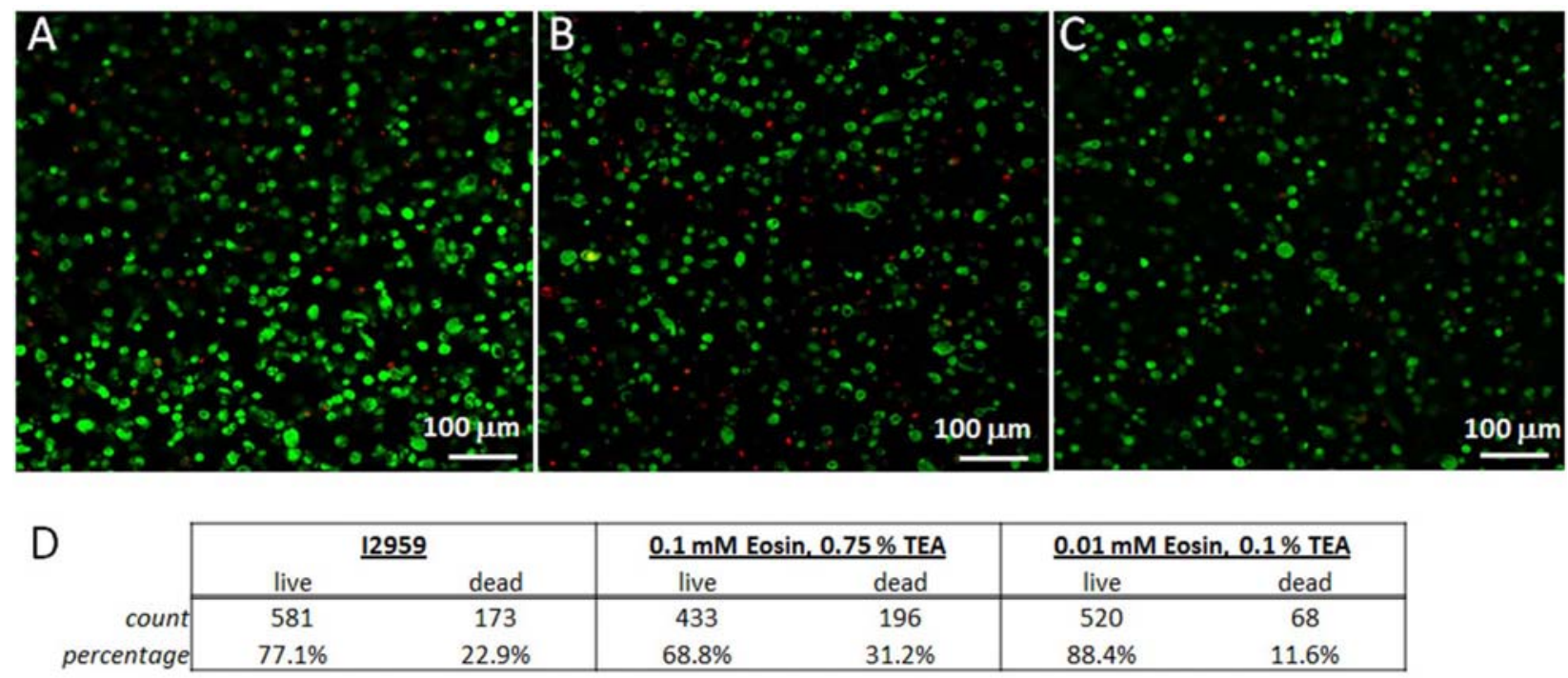

E

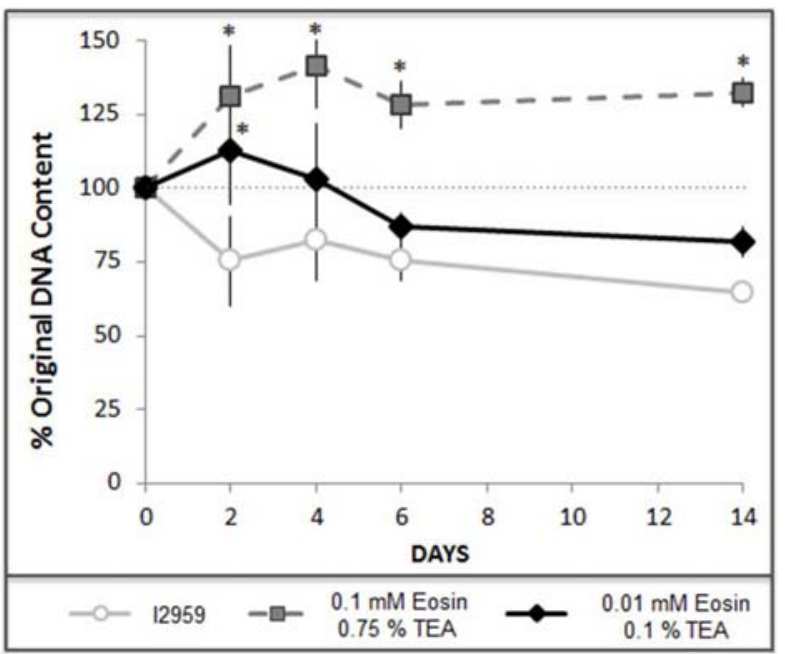

Fig. 4. Cytotoxicity of visible light initiation compared to UV light initiation. Live (green) - dead (red) staining of hMSCs $48 \mathrm{~h}$ after photoencapsulation in a $10 \%$ PEGDA scaffold using either (A) I2959, (B) $0.75 \%$ TEA \& $0.1 \mathrm{mM}$ eosin $\mathrm{Y}$, or (C) $0.1 \%$ TEA \& $0.01 \mathrm{mM}$ Eosin Y, (D) Quantification of livedead staining, (E) DNA content normalized to initial seeding density (DNA immediately after photoencapsulation, $p<0.05$ compared to I2959 control).

exposed to a mixture of $0.25 \mathrm{mM}$ calcein $\mathrm{AM}$ and $0.5 \mathrm{mM}$ EthD-1 in PBS for $40 \mathrm{~min}$ in the incubator $\left(37^{\circ} \mathrm{C}, 5 \%\right.$ $\mathrm{CO}_{2}$ ). Hydrogels were removed from the mixture, placed into PBS and fluorescence visualized immediately using confocal microscopy (Zeiss (Oberkochen, Germany) LSM$710,20 \mathrm{X}$ objective, 0.80 apopart). Viability was quantified by counting live (green) and dead (red) cells in 8 different microscopic fields representing 4 from the middle and 4 from the edge of representative hydrogels (observer was blinded as to which sample was which).

\section{Biochemical assays}

Hydrogels were removed from culture media, washed twice with PBS and digested in $200 \mu \mathrm{L} 0.1 \mathrm{~N} \mathrm{NaOH}$ $+5 \mu \mathrm{L} 2 \mathrm{~N} \mathrm{NaOH}$ in a water bath overnight at $60{ }^{\circ} \mathrm{C}$. Samples were neutralized with $0.1 \mathrm{~N} \mathrm{HCl}$ and then digested for an additional $18 \mathrm{~h}$ at $60{ }^{\circ} \mathrm{C}$ with $125 \mu \mathrm{g} /$ $\mathrm{mL}$ papain in $10 \mathrm{mM}$ EDTA, $2 \mathrm{mM}$ cysteine, $\mathrm{pH} 6.0$ (Sigma, St. Louis, MO). Sulfated glycosaminoglycan (GAG) content of the digested cell-polymer construct was assessed spectrophotometrically (575 nm) using the 1,9-dimethylmethylene blue (DMMB) dye assay (Polysciences, Warrington, PA, USA; pH 3.0) (Farndale et al., 1986). Sample GAG content was compared to shark cartilage chondroitin sulfate standards (Sigma-Aldrich) diluted in the papain buffer solution. For measuring
GAG released from the hydrogels, medium aspirates were collected weekly and the DMMB assay run against chondroitin sulfate standards diluted in DMEM medium. DNA content was determined spectrofluorimetrically using the PicoGreen fluorescent DNA binding dye assay according to manufacturer's instructions ( $\mathrm{P}$ 7581, Molecular Probes, Eugene, OR, USA). Sample fluorescence was compared to $\mu$ DNA standards included in the kit. Total collagen content was determined by oxidation of hydroxyproline residues in collagen with chloramine T trihydrate (ICN Biomedicals, Aurora, OH, USA), developed with p-dimethylaminobenzaldehyde (Ehrlich's reagent, ICN Biomedicals) (Sanford et al., 1997). Hydroxyproline content represents total collagen synthesis (Sanford et al., 1997). Sample concentrations were compared to hydroxyproline standard solutions made from trans-4-hydroxy-L-proline (Fluka/SigmaAldrich). All biochemical values represent mean \pm 95 $\%$ confidence of replicate ( 3 or more) samples from 3 different patient donors. Statistical significance was tested with the Dunnett's test for data determined to be normal by the Shapiro-Wilk test for goodness of fit (Fig. 5), or with the Mann-Whitney Rank Sum test for non-parametric data (Fig. 6): p-values less than 0.05 were considered significant. 


\section{Histology and immunohistochemistry}

Hydrogels were fixed in $10 \%$ neutral buffered formalin, embedded in paraffin and sectioned onto slides at $5 \mu \mathrm{m}$. Representative slides were deparaffinized and stained with toluidine blue to visualize sulfated proteoglycans. For immunohistochemistry, slides were deparaffinized and then blocked in $5 \%$ BSA for $1 \mathrm{~h}$ at room temperature. For collagen II detection, sections were exposed to pronase ( $1 \mathrm{mg} / \mathrm{mL}$ in PBS, $20 \mathrm{~min}$ ) at room temperature prior to reaction with a 1:200 dilution of monoclonal anti-collagen II antibody (II-II6B3, NIH Hybridoma Bank, University of Iowa, Ames, IA, USA) in $1 \%$ BSA, overnight at $4{ }^{\circ} \mathrm{C}$. Detection was done using a 1:500 dilution of the goat-antimouse AlexaFlour ${ }^{\mathrm{TM}} 594$ secondary antibody.

\section{Results}

Irgacure $^{\mathrm{TM}} 2959$ (I2959) is a commonly used photoinitiator for encapsulation of cells within hydrogels due to its wellestablished cytocompatibility below a concentration of 0.1 $\%(\mathrm{w} / \mathrm{v})$. When we incorporated peptides into PEGDA scaffolds to impart biological activity we found that I2959 could not effectively initiate photopolymerization at concentrations below $0.3 \%$, well above the cytotoxicity point for hMSCs. A number of peptide sequences were tested, but common to them all was the presence of the aromatic amino acid tryptophan. Since aromatic amino acids absorb energy at $285 \mathrm{~nm}$ we hypothesized that their presence in the macromer was competing with I2959 during the polymerization reaction (Fig. 1A, D) and were motivated to develop a photoinitiator effective in the visible light spectrum for encapsulation of hMSCs within peptide containing PEGDA hydrogels.

Eosin $\mathrm{Y}$ is a photosensitizer with peak absorbance of $510 \mathrm{~nm}$ (Fig. 1C) and can be used in conjunction with the initiator TEA and catalyst NVP for photopolymerization under bright white light. In preliminary experiments we found the published concentrations of eosin Y $(\geq$ $0.1 \mathrm{mM})$ and TEA $(\geq 1.5 \% \mathrm{w} / \mathrm{v})$, but not NVP $(37.5$ $\mathrm{nM}$ ), to be toxic to hMSCs. Cytotoxicity was tested by exposing confluent, monolayer-plated hMSCs to each initiator components for $5 \mathrm{~min}$, both with and without exposure to visible light in a similar fashion to earlier studies (Bryant et al., 2000; Williams et al., 2005). Using fluorescently activated calcein, live cells were visualized both immediately following treatment and $24 \mathrm{~h}$ later. Eosin $\mathrm{Y}$, at a concentration of $0.1 \mathrm{mM}$, was toxic to hMSCs only when activated by white light, presumably due to the presence of free radicals that could not be adequately quenched by the polymerization reaction. In contrast, TEA was toxic to the hMSCs both with and without exposure to light at a concentration of $1.5 \%$.

To determine lower concentrations of eosin Y and TEA that were still effective in initiating photopolymerization of a $10 \%(w / v)$ PEGDA, we created a fractional factorial test design that measured dynamic modulus and swelling ratio for hydrogels formed with $0.001-0.1 \mathrm{mM}$ eosin $\mathrm{Y}$ and $0.01-1.5 \%$ TEA (Fig. 2A). These physical properties of the scaffold can be used as a functional outcome measurement of the polymer network, with increased

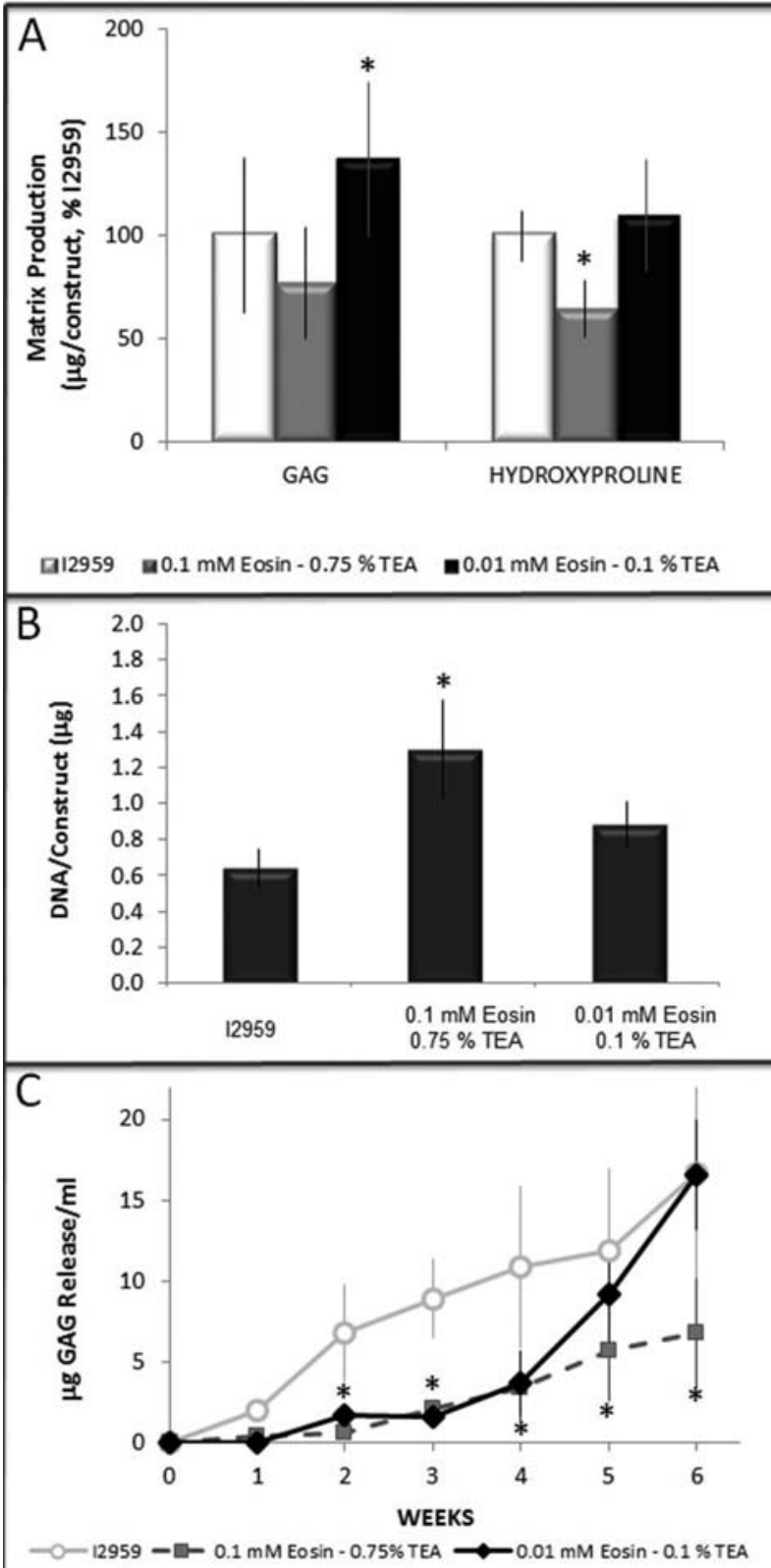

Fig. 5. hMSCs chondrogenesis in $10 \%$ PEGDA scaffolds polymerized with visible versus UV light. (A) GAG $(p=0.041)$ and total collagen accumulation $(p=$ 0.046) of eosin-TEA polymerized hydrogels normalized to I2959-scaffolds, (B) DNA content measured after 6 weeks $(p=0.015),(\mathbf{C})$ GAG release into the medium $(p<0.05$ compared to $\mathrm{I} 2959$ control).

dynamic modulus or decreased swelling ratio indicating either smaller pore size or higher crosslinking density. By establishing a relationship between the physical properties of a scaffold and initiator concentrations we aimed to decrease the concentrations of both eosin $\mathrm{Y}$ and TEA without compromising scaffold formation during the photopolymerization reaction. Using a customized apparatus to deliver force-controlled dynamic stimulation in unconfined compression to hydrogel constructs after they reached swelling equilibrium we found that modulus was not a linear function of concentration of either eosin Y or TEA, but rather that scaffold properties were 

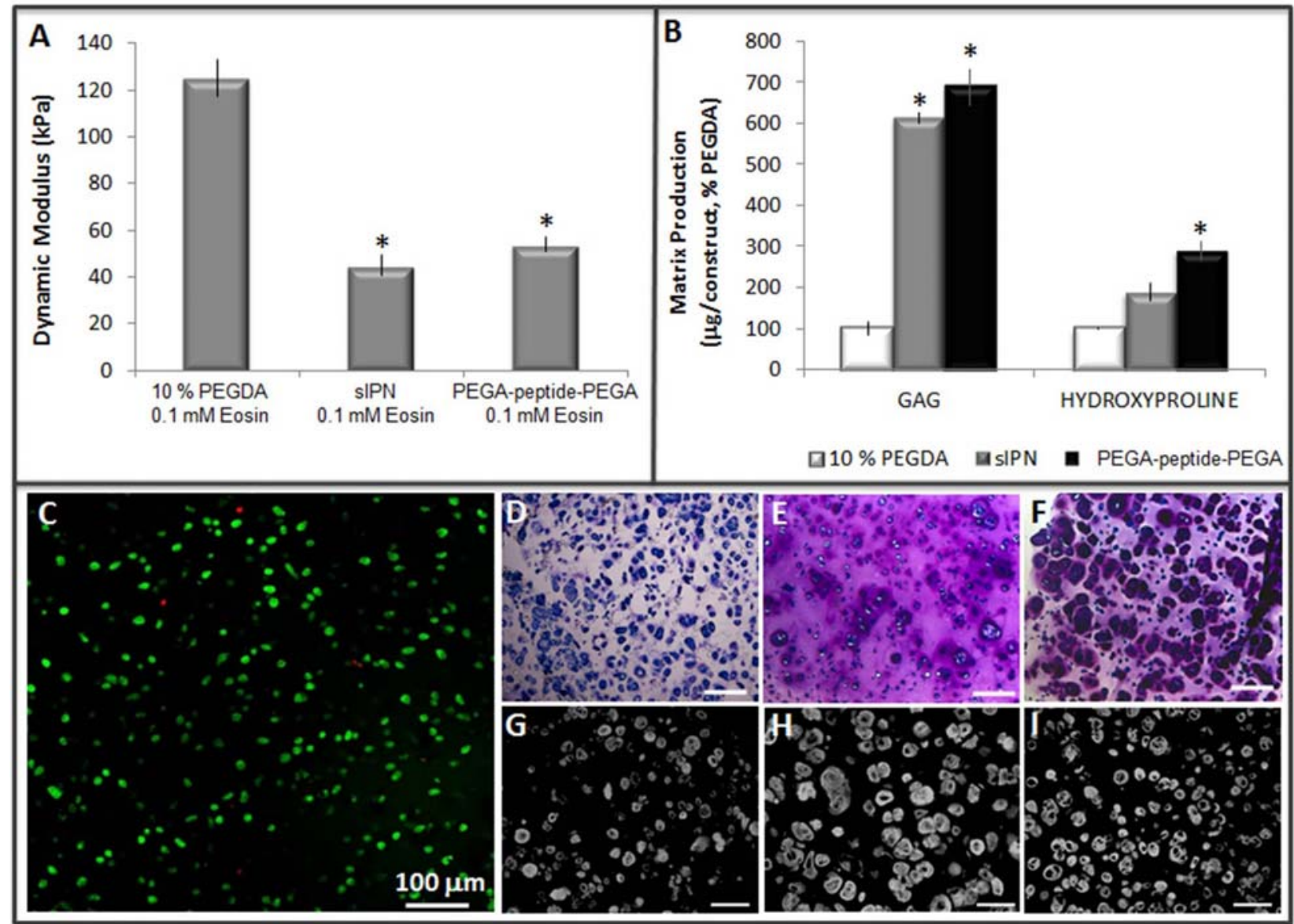

Fig. 6. hMSCs chondrogenesis using visible light initiator. (A) Dynamic compressive modulus of cell-free scaffolds following equilibrium swelling ( $p<0.0001)$, (B) GAG $(p<0.0002)$, and total collagen $(p=0.016)$ accumulation normalized to $10 \%$ PEGDA following six weeks of in vitro culture, (C) Live (green) - dead (red) staining of hMSCs in the PEGA-peptide-PEGA scaffold $48 \mathrm{~h}$ following photoencapsulation, $91.6 \%$ viability. Toluidine blue staining for proteoglycans following six weeks of in vitro culture in (D) $10 \%$ PEGDA, (E) sIPN, (F) PEGA-peptide-PEGA, scale bar $=200 \mu \mathrm{m}$. Collagen II immunohistochemistry following six weeks of in vitro culture in (G) $10 \%$ PEGDA, (H) sIPN, (I) PEGA-peptide-PEGA, scale bar $=100 \mu \mathrm{m}$

similar until one of the initiator component was below the essential concentration and then the reaction did not go to completion (Fig. 2). For analytical purposes polymerization was considered incomplete if greater than $25 \%$ of the original macromer volume did not react (Fig. 2A, groups G-I). Neither extending the time of light exposure from 2 to $10 \mathrm{~min}$, nor doubling the concentration of the catalyst NVP, was sufficient to carry the polymerization reaction to completion at these initiator concentrations. This relationship was modeled using a three-dimensional contour plot of the data generated using JMP ${ }^{\circledR}$ software (Fig. 2B). Although some variation was noted in the physical properties of the scaffold between groups A-F (Figure 2C, D: $p<0.05$ ), the differences were not considerable in comparison to the changes in physical properties observed when the macromer chemistry was changed (Fig. 3).

To test cytocompatibility during photoencapsulation of hMSCs in a $10 \%$ PEGDA scaffold we chose both a "high" (0.1 mM eosin Y and $0.75 \%$ TEA) and "low" $(0.01 \mathrm{mM}$ eosin $\mathrm{Y}$ and $0.1 \%$ TEA) concentration of eosin $\mathrm{Y}$ and TEA from our previous screen to compare with I2959 as a control. Although there were lower concentrations of eosin Y and TEA that were capable of initiating polymerization we chose not to test photoinitiator concentrations near the limit of an effective reaction (Fig. 2A, D-F) since the high density of cells can interfere with photopolymerization. Scaffolds formed by either visible light photopolymerization reaction had significantly higher crosslinking density than those formed with I2959 and UVlight as demonstrated by a higher dynamic compressive modulus (Fig. 3A, $p<0.0001$ ) and smaller swelling ratio (Fig. $3 \mathrm{~B}, p<0.005$ ). This translated into a smaller theoretical mesh size for the polymer scaffolds made with the visible light photoinitiator system (Table 2).

Cytotoxicity of the visible light initiator was evaluated with live-dead staining of hMSCs $48 \mathrm{~h}$ after photoencapsulation (Fig. 4A-D) and by quantifying DNA content in the hydrogels during through the first two weeks of culture (Fig. 4E). The live-dead staining indicated that maximal viability, $88.4 \%$, was achieved in hydrogels synthesized with the low concentration of eosin Y $(0.01$ $\mathrm{mM})$ and TEA $(0.1 \%)$ as compared with $77.1 \%$ viability in the I2959 control or $68.8 \%$ in the higher concentration of eosin Y $(0.1 \mathrm{mM})$ and TEA $(0.75 \%)$ (Fig. 4D). To evaluate whether there was a more long-term impact of 
Table 2. Molecular weight between crosslinks $\left(\mathrm{M}_{\mathrm{c}}\right)$ and mesh size $(\xi)$ calculated.

\begin{tabular}{|c|c|c|c|c|}
\hline $\begin{array}{l}\text { Hydrogel } \\
\text { Chemistry }\end{array}$ & Photoinitiator & $\mathbf{Q}$ & $\begin{array}{c}\mathrm{M}_{\mathrm{c}} \\
{[\mathrm{g} / \mathrm{mol}]}\end{array}$ & $\begin{array}{c}\xi \\
{[\mathrm{nm}]}\end{array}$ \\
\hline $10 \%$ PEGDA & I2959 & $12.9 \pm 1.2$ & 1471 & 5.4 \\
\hline $10 \%$ PEGDA & $\begin{array}{l}0.1 \mathrm{mM} \text { Eosin } \mathrm{Y} \\
0.75 \% \text { TEA }\end{array}$ & $9.1 \pm 0.25$ & 816 & 3.7 \\
\hline $10 \%$ PEGDA & $\begin{array}{l}0.01 \mathrm{mM} \text { Eosin } \mathrm{Y} \\
0.1 \% \text { TEA }\end{array}$ & $9.0 \pm 0.39$ & 794 & 2.7 \\
\hline sIPN & I2959 & $14.0 \pm 2.2$ & 1594 & 5.8 \\
\hline sIPN & $\begin{array}{l}0.01 \mathrm{mM} \text { Eosin } \mathrm{Y} \\
0.1 \% \text { TEA }\end{array}$ & $12.3 \pm 0.50$ & 1304 & 5.2 \\
\hline $\begin{array}{l}\text { PEGA-peptide- } \\
\text { PEGA }\end{array}$ & $\begin{array}{l}0.01 \mathrm{mM} \text { Eosin } \mathrm{Y} \\
0.1 \% \text { TEA }\end{array}$ & $14.1 \pm 0.22$ & 1789 & 6.3 \\
\hline
\end{tabular}

the photoinitiators on cell viability or proliferation we quantified DNA content in the visible light hydrogels and compared it to DNA in I2959-formed scaffolds over the course of two weeks; DNA content was normalized to the initial seeding density for each patient group (Fig. 4E, $p<$ $0.05)$. I2959 polymerized hydrogels had a lower relative number of cells at all times than either of the eosin-TEA polymerized hydrogels, however, this is likely due more to cell loss from the scaffold as a consequence of the larger mesh size (Fig. 3 and Table 2) than increased toxicity (Fig. 4D).

We next tested if hMSC chondrogenesis was differentially affected by the UV versus visible light polymerization process in $10 \%$ PEGDA scaffolds (Fig. 5). The higher concentration of the visible light initiator $(0.1 \mathrm{mM}$ eosin $\mathrm{Y}$ and $0.75 \%$ TEA) resulted in decreased accumulation of both sulfated proteoglycans ("GAGs", $192 \pm 30 \mu \mathrm{g})$ and collagen $(26 \pm 7 \mu \mathrm{g}, p=0.041)$ on a per construct basis than the control constructs formed with I2959 and UV light $(\mathrm{GAG}=250 \pm 93 \mu \mathrm{g}$, collagen $36 \pm$ $11 \mu \mathrm{g}$ ) following six weeks of in vitro culture (Figure 5A). Conversely, the lower concentration of the visible light initiator $(0.01 \mathrm{mM}$ eosin Y \& $0.1 \%$ TEA) accumulated significantly more sulfated proteoglycans per construct (343 $\pm 91 \mu \mathrm{g}, p=0.046)$ than the I2959 hydrogels $(250 \pm$ $93 \mu \mathrm{g})$, and did not impact collagen retention $(44 \pm 10 \mu \mathrm{g})$. The negative impact of the higher concentration of eosinTEA photoinitiators on chondrogenesis was amplified on a per cell basis considering DNA content was significantly higher in these scaffolds (Fig. 5B, $p=0.015$ ). We also quantified GAG release to the media from each of these scaffolds: more GAG was released from the 12959 scaffolds between weeks 2-4 (Fig. 5C, $p<0.05$ ), presumably due to the lower crosslinking density (Fig. 3, Table 2). GAG release from the lower concentration of eosin-TEA was reduced compared to 2959 initially, but reached the same levels by weeks 5 and 6 (Fig. 5C), consistent with the higher crosslinking density (Fig. 3, Table 2) and higher GAG total accumulation (Fig. 5A). GAG release from the higher eosin-TEA scaffold remained consistently low despite the higher number of cells (Figs. 4E and 5B).

This visible light photoinitiator was also effective in initiating polymerization of scaffolds containing peptides with aromatic amino acids (PEGA-peptide-PEGA); polymerization of this scaffold was not possible with I2959 at a concentration below $0.1 \%(\mathrm{w} / \mathrm{v})$. Live-dead staining of hMSCs encapsulated in the PEGA-peptide-PEGA hydrogel confirmed cytocompatibility with $91.6 \%$ viability observed at $48 \mathrm{~h}$ post-encapsulation (Fig. 6C). We next compared chondrogenesis of hMSCs in the $10 \%$ PEGDA, PEGApeptide-PEGA and a PEGDA-based semi-interpenetrating network (sIPN) in which we have previously shown improved matrix production and distribution during hMSC chondrogenesis due to the increased pore size in the sIPN scaffold (Buxton et al., 2007). Chondrogenesis was improved in both the sIPN and PEGA-peptide-PEGA scaffolds when compared to $10 \%$ PEGDA scaffolds, as measured by accumulation of extracellular matrix proteins (Fig. 6B) and visualized with toluidine blue (Fig. 6D-I) and type II collagen immunohistochemistry (Fig. 6G-J). Proteoglycan accumulation per construct after six weeks of in vitro culture was only $192 \pm 38 \mu \mathrm{g}$ in the $10 \%$ PEGDA scaffolds compared with $1181 \pm 81 \mu \mathrm{g}$ and 1331 $\pm 373 \mu \mathrm{g}$ in the sIPN and PEGA-peptide-PEGA scaffolds respectively. Collagen content per construct, measured by the hydroxyproline assay, was also significantly lower in the $10 \%$ PEGDA scaffolds $(26 \pm 7 \mu \mathrm{g})$ than the sIPN (49 $\pm 11 \mu \mathrm{g})$ or PEGA-peptide-PEGA $(76 \pm 18 \mu \mathrm{g})$ scaffolds. This similarity in neocartilage production between the SIPN and PEGA-peptide-PEGA scaffolds was likely the result of similar physical properties: the addition of the peptide into the PEGDA backbone increased the molecular weight of the crosslinking subunit and translated into a lower dynamic compressive modulus (Fig. 6A, $p<0.0001$ ) and correlated to an increased mesh size (Table 2).

\section{Discussion}

Recent advances in tissue engineering have generated new tools for creating scaffolds with biological activity. For example, by incorporating functional peptide sequences into the scaffold chemistry synthetic systems can direct cellular activity, such as stem cell differentiation (Hwang et al., 2008; Lutolf et al., 2009), or respond to the evolving needs of the developing tissue (Bahney et al., 2011; Chan 
and Mooney, 2008). Critical to the successful application of these novel biomaterials is developing non-toxic methods to deliver cells. The primary goals of this study were to establish cytocompatible conditions for photoencapsulation of hMSCs using a visible light initiator system and to study the impact of this initiator system on chondrogenesis. This study was prompted by the finding that the addition of peptides containing aromatic amino acids interfered with photopolymerization of bioresponsive PEGDA using the most commonly applied UV initiator, I2959. Visible light initiator systems offer potential benefits for photoencapsulation of hMSCs in bioresponsive scaffolds: (1) the longer wavelength activation of the initiator would not compete in the UV spectrum at which both aromatic amino acids and I2959 absorb, allowing effective polymerization of peptide modified PEGDA hydrogels, (2) that cytocompatible visible light photoinitiators would eliminate any potential cellular toxicity imparted by UV radiation, and (3) the visible light initiator will reduce the risk of peptide denaturation during UV exposure.

By using a fractional factorial screening design to modify a visible light photoinitiator system comprised of the photosensitizer eosin Y, initiator TEA, and accelerator NVP (Cruise et al., 1998; Bikram et al., 2007) we screened for photoinitiator concentrations that were effective in initiating polymerization with a visible light source (Fig. 2B). Based on these parameters we were able to compare cytotoxicity and chondrogenesis of hMSCs in a visible light system to the well-characterized UV encapsulation technique that uses the photoinitiator I2959. We show that the initiator system can impact chondrogenesis by both having a direct toxicity and by changing the physical properties of the scaffold. A low concentration of the visible light initiator components $(0.01 \mathrm{mM}$ eosin, $0.1 \%$ TEA, $37.5 \mathrm{nM}$ NVP) supports chondrogenic differentiation of encapsulated hMSCs and produces a scaffold with higher dynamic compressive modulus than a similar scaffold formed by UV light and the initiator I2959.

Direct toxicity of the photoinitiator can be caused by either the light source or the chemical initiators. UV light is a well-established genetic mutagen at the lower wavelengths at which 12959 has a peak absorbance (Ananthaswamy and Pierceall, 1990; Cadet et al., 1997; Griffiths et al., 1998). Although I2959 is thought to remain an effective initiator at $365 \mathrm{~nm}$, which is better tolerated by the cells, its absorption is significantly reduced at this wavelength (Bryant et al., 2000) and we show its activity is severely compromised when combined with peptides that also absorb light in the UV range. Another concern with the low absorbance of I2959 at $365 \mathrm{~nm}$ is that relatively long UV exposures times ( $>5 \mathrm{~min}$ ) are required to effectively complete the photopolymerization reaction (Buxton et al., 2007). Although the perceived direct damage to the cells with this exposure is relatively low, it has been shown that some cell types are extremely sensitive to UV exposure (Williams et al., 2005) and that this potentially adverse effect should be accounted for in optimizing a tissue engineered system. The visible light initiator system we developed here works with bright white light that offers significantly reduced risk for genetic mutagenesis (Kielbassa et al., 1997) and produces more tightly crosslinked networks with brief exposure times between 1-2 min.

The chemical toxicity of the initiator reagents is also a concern. I2959 has limited toxicity below $0.1 \%$ (Bryant et al., 2000; Williams et al., 2005; Fedorovich et al., 2009;), although some cells show variable degrees of cytocompatibility (Williams et al., 2005). A number of other visible light initiators have previously been described to have a cytotoxic effect, including 9-fluorenone and camphorquinone (CQ) used with either ethyl 4-N, $\mathrm{N}$-dimethylaminobenzoate or TEA and the photosensitizer isopropyl thioxanthone (Atsumi et al., 1998; Bryant et al., 2000). In this study we chose to modify a visible light photoinitiator system comprised of photosensitizer eosin Y, initiator TEA, and accelerator NVP that has previously been tested in other applications (Cruise et al., 1998; Bikram et al., 2007), but not employed for chondrogenesis of encapsulated hMSCs. Cytotoxicity during polymerization reactions has previously been tested predominantly using exposure of monolayerplated cells to initiator components and light (Bryant et al., 2000; Williams et al., 2005). Using this technique to screen for toxicity of eosin Y and TEA in preliminary experiments we found that free radicals generated during light-activation of eosin $\mathrm{Y}$ were very toxic to cells at a concentration of $0.1 \mathrm{mM}$. TEA had a toxic effect both with and without light exposure at a concentration of $1.5 \%$ $(\mathrm{v} / \mathrm{v})$. However, this method for establishing toxicity does not adequately account for the quenching of radicals that occurs during the process of radical chain polymerization of functionalized macromers. Consequently, our toxicity experiments examined DNA content, cell viability, and chondrogenic capacity of hMSCs within a $10 \%$ PEGDA hydrogel. When we used these methods to evaluate two different concentrations of the eosin y based initiator system we found chemical toxicity could impact both cell viability in the short term (Fig. 4) and differentiation capacity (Fig. 5), as suggested previously in studies of I2959 and its impact on osteogenesis (Fedorovich et al., 2009). Furthermore, our study revealed that even at the lowest effective concentrations of the eosin y-TEA initiator system, the resultant hydrogel scaffolds were significantly stronger than hydrogels produced with I2959 under commonly used UV-initiated conditions (Figure 3). Physical properties are known to have direct effect on stem cell differentiation (Discher et al., 2005; Ghosh and Ingber, 2007), while mesh size can influence the elaboration of extracellular matrix (Bryant et al., 1999b; Buxton et al., 2007; Erickson et al., 2009) that is essential for functional tissue regeneration. Consequently following the validation of $0.01 \mathrm{mM}$ eosin $\mathrm{Y}$ and $0.1 \%$ TEA as a safe photoinitiator for hMSC chondrogenesis we next chose to explore how physical and peptide modifications to the scaffold would impact chondrogenesis.

We compared chondrogenesis of hMSCs in the $10 \%$ PEGDA hydrogels to both a PEGDA-based sIPN and a PEGA-peptide-PEGA scaffold. The PEGA-peptide-PEGA scaffold was representative of bioresponsive hydrogels designed to be enzymatically degradable (West and Hubbell, 1999; Mann et al., 2001a; Lutolf et al., 2003; Park et al., 2004b; Bahney et al., 2011), but we chose to use a 
peptide with no known biological activity (Rawlings et al., 2008) to prevent confounding the effect on chondrogenesis. The PEGDA-based sIPN scaffold was included because we have previously published an improved extracellular matrix production and distribution during chondrogenesis of hMSCs due to the larger pores formed by the inclusion of a non-crosslinking PEG component (Buxton et al., 2007). The larger pore size in the sIPN is illustrated by the significantly reduced dynamic compressive modulus as compared with $10 \%$ PEGDA and increased mesh size. We achieved approximately the same physical properties as the SIPN scaffold in the $10 \%$ PEGDA hydrogel with a peptide embedded into the scaffold backbone (PEGApeptide-PEGA). The presence of the peptide increased the molecular weight of the crosslinking monomer subunit from unmodified $6 \mathrm{kDa}$ for the PEGDA, to $8.27 \mathrm{kDa}$ for the PEGA-peptide-PEGA. Molecular weight has previously been shown to have a significant impact on crosslinking density (Bryant et al., 1999b; Bryant and Anseth, 2002; Bryant et al., 2003; Hahn et al., 2007), explaining the change in the physical properties of the PEGA-peptidePEGA hydrogel relative to the $10 \%$ PEGDA scaffold. Chondrogenesis in these three scaffolds was compared following six weeks of in vitro culture and we found significantly greater proteoglycan accumulation and distribution in both the sIPN and PEGA-peptide-PEGA scaffold than in $10 \%$ PEGDA, all when polymerized with the visible light initiator. Collagen accumulation was significantly higher in the PEGA-peptide-PEGA scaffold but distribution did not change, perhaps due to the large size of the assembled collagen II fibers and the fact that this modification did not render the scaffold degradable (Bahney et al., 2011). Together these data indicate that photoinitiator chemistry can impact the tissue engineering system by affecting cellular viability, differentiation capacity and the physical properties of the scaffold.

\section{Conclusions}

An important part of validating scaffold design for differentiation of stem cells is the consideration of the chemical toxicity of the photoinitiator and how changes to the physical properties of a scaffold can impact cellular behavior. This study validates a visible light photoinitiator system comprised of $0.01 \mathrm{mM}$ eosin Y, $0.1 \%$ TEA, and $37.5 \mathrm{nMNVP}$ for cytocompatible encapsulation of hMSCs. We found this photoinitiator system to be more suitable for creating scaffolds containing peptides as the absorbance of aromatic amino acids can interfere with polymerization reactions in the UV light range. The visible light system changed the physical properties of the same scaffold relative to photoinitiation using I2959; compared to scaffolds made from I2959, both concentration of initiator were sufficient to increase the dynamic compressive modulus of the resultant scaffold by at least $120 \%$ with a polymerization time of only 2 min as compared with 6 min for I2959. Using this visible light initiating system we then compared hMSC chondrogenesis in a $10 \%$ PEGDA, PEGDA-based sIPN, and peptide containing scaffold (PEGA-peptidePEGA) representative of bioresponsive scaffolds. We found that scaffold mesh size had a significant impact on matrix elaboration, with looser networks increasing matrix deposition and improving distribution of proteoglycans.

\section{Acknowledgements}

The authors would like to thank Drs. Jung Yoo, Bob Hart and Alex Ching (OHSU, Portland, OR) for providing bone marrow aspirates following patient consent and Dr. Melissa McHale (Rice University, Houston TX) for reviewing the manuscript and useful discussions. Research was supported in part by grants from the Gerlinger Endowment (OHSU) and the National Football League Charities.

\section{Disclosure}

Dr. Johnstone receives royalties from the license of the patent for the method of in vitro chondrogenesis from Osiris Therapeutics, Inc.

\section{References}

Ananthaswamy HN, Pierceall WE (1990) Molecular mechanisms of ultraviolet radiation carcinogenesis. Photochem Photobiol 52: 1119-1136.

Atsumi T, Murata J, Kamiyanagi I, Fujisawa S, Ueha T (1998) Cytotoxicity of photosensitizers camphorquinone and 9-fluorenone with visible light irradiation on a human submandibular-duct cell line in vitro. Arch Oral Biol 43: 73-81.

Bahney CS, Hsu CW, Yoo JU, West JL, Johnstone B (2011) A bioresponsive hydrogel tuned to chondrogenesis of human mesenchymal stem cells. FASEB J 25: 14861496.

Bikram M, Fouletier-Dilling C, Hipp JA, Gannon F, Davis AR, Olmsted-Davis EA, West JL (2007) Endochondral bone formation from hydrogel carriers loaded with BMP2-transduced cells. Ann Biomed Eng 35: 796-807.

Bryant SJ, Anseth KS (2002) Hydrogel properties influence ECM production by chondrocytes photoencapsulated in poly(ethylene glycol) hydrogels. J Biomed Mater Res 59: 63-72.

Bryant SJ, Anseth KS (2003) Controlling the spatial distribution of ECM components in degradable PEG hydrogels for tissue engineering cartilage. J Biomed Mater Res A 64: 70-79.

Bryant SJ, Martens P, Elisseeff JH, Randolph M, Langer R, Anseth KS (1999a) Transtissue photopolymerization of poly(vinyl alcohol) hydrogels in: Chemical and Physical Networks Formation and Control of Properties, vol 2 (Stokke BT, Elgsaeter A, eds) Wiley, New York, pp 395403.

Bryant SJ, Nuttelman CR, Anseth KS (1999b) The effects of crosslinking density on cartilage formation in photocrosslinkable hydrogels. Biomed Sci Instrum 35: 309-314.

Bryant SJ, Nuttelman CR, Anseth KS (2000) Cytocompatibility of UV and visible light photoinitiating 
systems on cultured NIH/3T3 fibroblasts in vitro. J Biomater Sci Polymer Ed 11: 439-457.

Bryant SJ, Durand KL, Anseth KS (2003) Manipulations in hydrogel chemistry control photoencapsulated chondrocyte behavior and their extracellular matrix production. J Biomed Mater Res A 67: 1430-1436.

Bryant SJ, Chowdhury TT, Lee DA, Bader DL, Anseth KS (2004) Crosslinking density influences chondrocyte metabolism in dynamically loaded photocrosslinked poly(ethylene glycol) hydrogels. Ann Biomed Eng 32: 407-417.

Buxton AN, Bahney CS, Yoo J, Johnstone B (2011) Temporal exposure to chondrogenic factors modulates human mesenchymal stem cell chondrogenesis in hydrogels. Tissue Eng Part A 17: 371-380.

Buxton AN, Zhu J, Marchant R, West JL, Yoo JU, Johnstone B (2007) Design and characterization of poly(ethylene glycol) photopolymerizable semiinterpenetrating networks for chondrogenesis of human mesenchymal stem cells. Tissue Eng 13: 2549-2560.

Cadet J, Berger M, Douki T, Morin B, Raoul S, Ravanat JL, Spinelli S (1997). Effects of UV and visible radiation on DNA-final base damage. Biol Chem 378: 1275-1286.

Canal T, Peppas NA (1989) Correlation between mesh size and equilibrium degree of swelling of polymeric networks. J Biomed Mater Res 23: 1183-1193.

Chan G, Mooney DJ (2008) New materials for tissue engineering: towards greater control over the biological response. Trends Biotechnol 26: 382-392.

Cruise GM, Hegre OD, Scharp DS, Hubbell JA (1998) A sensitivity study of the key parameters in the interfacial photopolymerization of poly(ethylene glycol) diacrylate upon porcine islets. Biotechnol Bioeng 57: 655-665.

Discher DE, Janmey P, Wang YL (2005) Tissue cells feel and respond to the stiffness of their substrate. Science 310: 1139-1143.

Erickson IE, Huang AH, Sengupta S, Kestle S, Burdick JA, Mauck RL (2009) Macromer density influences mesenchymal stem cell chondrogenesis and maturation in photocrosslinked hyaluronic acid hydrogels. Osteoarthritis Cartilage 17: 1639-1648.

Fan VH, Tamama K, Au A, Littrell R, Richardson LB, Wright JW, Wells A, Griffith LG (2007) Tethered epidermal growth factor provides a survival advantage to mesenchymal stem cells. Stem Cells 25: 1241-1251.

Farndale RW, Buttle DJ, Barrett AJ (1986) Improved quantitation and discrimination of sulphated glycosaminoglycans by use of dimethylmethylene blue. Biochim Biophys Acta 883: 173-177.

Fedorovich NE, Oudshoorn MH, van Geemen D, Hennink WE, Alblas J, Dhert WJ (2009). The effect of photopolymerization on stem cells embedded in hydrogels. Biomaterials 30: 344-353.

Flory PJ, Rehner Jr RJ (1943) Statistical mechanics of crosslinked polymer networks II. Swelling. J Chem Phys 11: $521-526$

Ghosh K, Ingber DE (2007) Micromechanical control of cell and tissue development: implications for tissue engineering. Adv Drug Deliv Rev 59: 1306-1318.

Graham NB (1998a) Hydrogels: their future, Part I. Med Device Technol 9:18-22.
Graham NB (1998b) Hydrogels: their future, Part II. Med Device Technol 9: 22-25.

Griffiths HR, Mistry P, Herbert KE, Lunec J (1998) Molecular and cellular effects of ultraviolet light-induced genotoxicity. Crit Rev Clin Lab Sci 35: 189-237.

Hahn MS, McHale MK, Wang E, Schmedlen RH, West JL (2007) Physiologic pulsatile flow bioreactor conditioning of poly(ethylene glycol)-based tissue engineered vascular grafts. Ann Biomed Eng 35: 190-200.

Harbers GM, Healy KE (2005) The effect of ligand type and density on osteoblast adhesion, proliferation, and matrix mineralization. J Biomed Mater Res A 75: 855-869.

Hwang NS, Varghese S, Elisseeff J (2008) Controlled differentiation of stem cells. Adv Drug Deliv Rev 60: 199214.

Hwang NS, Varghese S, Zhang Z, Elisseeff J (2006) Chondrogenic differentiation of human embryonic stem cell-derived cells in arginine-glycine-aspartate-modified hydrogels. Tissue Eng 12: 2695-2706.

Johnstone B, Hering TM, Caplan AI, Goldberg VM, Yoo JU (1998) In vitro chondrogenesis of bone marrowderived mesenchymal progenitor cells. Exp Cell Res 238: 265-272.

Kielbassa C, Roza L, Epe B (1997) Wavelength dependence of oxidative DNA damage induced by UV and visible light. Carcinogenesis 18: 811-816.

Kim S, Chung EH, Gilbert M, Healy KE (2005). Synthetic MMP-13 degradable ECMs based on poly(Nisopropylacrylamide-co-acrylic acid) semi-interpenetrating polymer networks. I. Degradation and cell migration. J Biomed Mater Res A 75: 73-88.

Kisiday JD, Jin M, DiMicco MA, Kurz B, Grodzinsky AJ (2004). Effects of dynamic compressive loading on chondrocyte biosynthesis in self-assembling peptide scaffolds. J Biomech 37: 595-604.

Kohane DS, Langer R (2008). Polymeric biomaterials in tissue engineering. Pediatr Res 63: 487-491.

Lujan TJ, Underwood CJ, Jacobs NT, Weiss JA (2009) Contribution of glycosaminoglycans to viscoelastic tensile behavior of human ligament. J Appl Physiol 106: 423-431.

Lujan TJ, Wirtz KM, Bahney CS, Madey SM, Johnstone B, Bottlang M (2011) A novel bioreactor for the dynamic stimulation and mechanical evaluation of multiple tissue-engineered constructs. Tissue Eng Part C Methods 17: 367-374.

Lutolf MP (2009) Biomaterials: Spotlight on hydrogels. Nat Mater 8: 451-453.

Lutolf MP, Gilbert PM, Blau HM (2009) Designing materials to direct stem-cell fate. Nature 462: 433-441.

Lutolf MP, Hubbell JA (2005) Synthetic biomaterials as instructive extracellular microenvironments for morphogenesis in tissue engineering. Nat Biotechnol 23: 47-55.

Lutolf MP, Lauer-Fields JL, Schmoekel HG, Metters AT, Weber FE, Fields GB, Hubbell JA (2003) Synthetic matrix metalloproteinase-sensitive hydrogels for the conduction of tissue regeneration: engineering cellinvasion characteristics. Proc Natl Acad Sci U S A 100: 5413-5418.

Mann BK, Gobin AS, Tsai AT, Schmedlen RH, West JL (2001a) Smooth muscle cell growth in photopolymerized 
hydrogels with cell adhesive and proteolytically degradable domains: synthetic ECM analogs for tissue engineering. Biomaterials 22: 3045-3051.

Mann BK, Schmedlen RH, West JL (2001b). TetheredTGF-beta increases extracellular matrix production of vascular smooth muscle cells. Biomaterials 22: 439-444.

Merrill EW, Dennison KA, Sung C (1993) Partitioning and diffusion of solutes in hydrogels of poly(ethylene oxide). Biomaterials 14: 1117-1126.

Nguyen KT, West JL (2002). Photopolymerizable hydrogels for tissue engineering applications. Biomaterials 23: 4307-4314.

Park S, Hung CT, Ateshian G. (2004a). Mechanical response of bovine articular cartilage under dynamic unconfined compression loading at physiological stress levels. Osteoarthritis Cartilage 12: 65-73.

Park Y, Lutolf MP, Hubbell JA, Hunziker EB, Wong M (2004b) Bovine primary chondrocyte culture in synthetic matrix metalloproteinase-sensitive poly(ethylene glycol)based hydrogels as a scaffold for cartilage repair. Tissue Eng 10: 515-522.

Peppas NA, Merrill EW (1976) Polybinyl-alcohol hydrogels - reinforcement of radiation-crosslinked networks by crystallization. J Polym Sci Polym Chem 14: 441-457.

Place ES, Evans ND, Stevens MM (2009) Complexity in biomaterials for tissue engineering. Nat Mater 8: 457470.

Rawlings N, Morton R, Kok C, Kong J, Barrett A(2008) MEROPS: the peptide database. Nucleic Acids Res 36: D320-D325.

Rice MA, Sanchez-Adams J, Anseth KS (2006) Exogenously triggered, enzymatic degradation of photopolymerized hydrogels with polycaprolactone subunits: experimental observation and modeling of mass loss behavior. Biomacromolecules 7: 1968-1975.

Ringe J, Sittinger M (2009) Tissue engineering in the rheumatic diseases. Arthritis Res Ther 11: 211.

Salinas CN, Anseth KS (2008) The influence of the RGD peptide motif and its contextual presentation in PEG gels on human mesenchymal stem cell viability. J Tissue Eng Regen Med 2: 296-304.

Sanford LP, Ormsby I, Gittenberger-de Groot AC, Sariola H, Friedman R, Boivin GP, Cardell EL, Doetschman T (1997) TGF $\beta 2$ knockout mice have multiple developmental defects that are non-overlapping with other TGF $\beta$ knockout phenotypes. Development 124: 26592670.

Suzuki Y, Tanihara M, Suzuki K, Saitou A, Sufan W, Nishimura Y (2000) Alginate hydrogel linked with synthetic oligopeptide derived from BMP-2 allows ectopic osteoinduction in vivo. J Biomed Mater Res 50: 405-409.

Wall ST, Saha K, Ashton RS, Kam KR, Schaffer DV, Healy KE (2008) Multivalency of Sonic hedgehog conjugated to linear polymer chains modulates protein potency. Bioconjug Chem 19, 806-812.

West J, Hubbell J (1999) Polymeric biomaterials with degradation sites for protease involved in cell migration. Macromolecules 32: 241-244.

Williams CG, Malik AN, Kim TK, Manson PN, Elisseeff JH (2005) Variable cytocompatibility of six cell lines with photoinitiators used for polymerizing hydrogels and cell encapsulation. Biomaterials 26: 1211-1218.

Woodfield TB, Malda J, de Wijn J, Peters F, Riesle J, van Blitterswijk CA (2004) Design of porous scaffolds for cartilage tissue engineering using a three-dimensional fiber-deposition technique. Biomaterials 25: 4149-4161.

Yoo JU, Barthel TS, Nishimura K, Solchaga L, Caplan AI, Goldberg VM, Johnstone B (1998) The chondrogenic potential of human bone-marrow-derived mesenchymal progenitor cells. J Bone Joint Surg Am 80: 1745-1757.

\section{Discussion with Reviewer}

Reviewer I: Based on your results, would you recommend that all PEG hydrogels be made with this crosslinking system?

Authors: Not necessarily. The purpose of this publication was to emphasize that the photoinitiator is an important component of the tissue engineering system and should be appropriately optimized. Our work with a visible light photoinitiator for hMSC chondrogenesis was done to not only find non-toxic conditions for cell-encapsulation, but also to demonstrate that the photoinitiator can impact tissue development by changing the physical properties of a scaffold. The polymerization conditions described here were intended to expand the tissue engineer's toolbox for photoinitiators and methodologies by which to evaluate them.

Reviewer I: What are the advantages and disadvantages of using the Irgacure 2959 initiator compared to the photocrosslinking system developed here?

Authors: The biggest advantage of Irgacure 2959 is that it is a type I photoinitiator (cleavage type), meaning that you only need a single molecule for both the photoactivation and initiation of the crosslinking reaction. This is in contrast to the visible light system described here (type II photoinitiator) that requires three reagents. Furthermore, because I2959 has a peak absorbance at $280 \mathrm{~nm}$, it is likely to remain fairly stable when exposed to ambient light. Eosin $\mathrm{Y}$ is photosensitive under ambient conditions, meaning that more care needs to be taken when using this photoactivator. When considering translation of this technology to patient therapies, both light sources are commonly available in the operating room, but the reduced time for polymerization of the scaffold in a defect with the visible light initiator would be an important advantage to the surgeon.

Reviewer I: Are there some cases where one crosslinking system is preferred over the other?

Authors: The most obvious advantage of the visible light initiator system is in the case where peptides are included into the polymerization reaction: Irgacure 2959 cannot be used to effectively crosslink hydrogels at a cytocompatible concentration. Furthermore, UV light carries and implicit risk of denaturing the peptides and damaging cellular DNA during the photoencapsulation process. 